\title{
Avaliação da Eficácia da Limpeza e Lubrificação do Arame sobre a Alimentabilidade em MIG/MAG
}

\author{
Enzo Rafael de Araújo Moysés ${ }^{1}$, Thiago Aires Mendes ${ }^{1}$, Diandro Bailoni ${ }^{1}$, Américo Scotti $^{1}$ \\ 1 Universidade Federal de Uberlândia - UFU, Centro para Pesquisa e Desenvolvimento de Processos de Soldagem, Grupo \\ Laprosolda, Uberlândia, MG, Brasil.
}

Recebido: 20 Fev., 2018

Aceito: 06 Abr., 2018

E-mail: ascotti@ufu.br(AS)
Este é um artigo publicado em acesso aberto (Open Access) sob a licença Creative Commons Attribution Non-Commercial, que permite uso, distribuição e reprodução em qualquer meio, sem restriçōes desde que sem fins comerciais e que trabalho original seja corretamente citado.
Resumo: Analisou-se a eficácia de um "kit" de limpeza e lubrificação para arames de solda em relação à alimentabilidade do processo MIG/MAG. Soldagens comparativas de simples deposição sobre chapa na posição plana foram feitas, utilizando-se diferentes bicos de contato, assim como diferentes condições da superfície dos arames (normal e não conformes, oxidado e contaminado com detritos). Usou-se para qualificar a alimentabilidade um sistema dedicado constituído de uma célula de carga assistida por um sensor de queda de tensão no bico de contato. A eficácia do "kit" foi verificada pela variação da resistência elétrica do bico de contato e da força de alimentação, assim como pela aparência visual do arame na saída da tocha sem arco. O "kit" demonstrou ser eficaz, fazendo reduzir a força de alimentação sem aumentar a resistência elétrica dos bicos testados. Porém, não foi eficaz quando aplicado sobre um arame oxidado. Conclui-se que o "kit" é eficaz em casos onde o arame está em condições normais de uso ou apenas contaminado com detritos, reduzindo a fricção arame-tocha e facilitando a alimentabilidade do arame, mas não é suficiente para corrigir uma anomalia séria do arame (oxidação).

Palavras-chave: GMAW; Automação; Alimentabilidade de arame; Melhorias operacionais.

\section{Efficacy Assessment of Wire Cleaning and Lubrification on MIG/MAG Feedability}

Abstract: The efficacy of a cleaning and lubrication kit for welding wires was analysed in relation to the wire feedability in MIG/MAG process. Comparative bead-on-plate welds on flat position were carried out, using different contact tips, as well as different wire surface conditions (normal and non-conforming, oxidized and contaminated with debris). A dedicated system, consisting of a load cell assisted by a voltage drop sensor for the contact tip, was used to qualify the feedability. The effectiveness of the kit was verified by the variation of the contact tip electric resistance and the feeding force, as well as by the visual appearance of the wire without arc. The "kit" showed to be effective, reducing the feeding force without increasing the electrical resistance of the contact tip. However, it was not effective when applied over oxidized wires. It is concluded that the kit is effective in cases where the wire is in normal use or only contaminated with debris, reducing the wire-torch friction and facilitating wire feedability, but it is not sufficient to correct serious anomalies of the wire (oxidation).

Key-words: GMAW; Automation; Wire feedability; Operational improvements.

\section{Introdução}

Um dos problemas operacionais mais comuns no processo de soldagem MIG/MAG é a instabilidade da alimentação do arame. Tomando como base citações de Hajro e Hodžić (2004), pode-se mencionar entre os fatores que afetam a estabilidade da alimentação do arame a pressão e geometria dos roletes (que causam deformação no arame e, consequentemente, aumentam a força de fricção), a restrição de entrada no bico de contato (cuja resistência à passagem do arame causa flambagem e, em situações extremas, a parada da alimentação), o material, diâmetro e comprimento do conduíte (maior parte da fricção envolvida na passagem do arame), a configuração e posição de utilização da tocha (altera significativamente a resistência à alimentação), e, por último, o material de adição (arame), cujas condições de deformação (dobras e torção), de superfície (boa qualidade do cobreamento, por exemplo), bem como a sua tenacidade, são influentes nas características de alimentação. Outro fator responsável pelo aumento da fricção, assim também pela força de alimentação, segundo Lyttle (1982), é o acúmulo 
de detritos no sistema, principalmente por efeitos de desgaste mecânico no arame. Já Padilla et al. (2003) dão importância à fricção entre o arame e o conduíte.

Shimizu et al. (2006) desenvolveram um trabalho para mostrar a importância da fricção entre arame e bico de contato, motivados na citação de alguns autores de que o conhecimento dos fenômenos que atuam nos contatos deslizantes durante a soldagem ajudam no desenvolvimento de arame específicos com alimentabilidade superior. Estes autores, citando outros trabalhos, exemplificam com o fato de que o arame é distorcido helicoidalmente no conduíte e a força de fricção gerada pelo contato arame/parede do conduíte é causa de resistência à alimentação. O aumento dessa força de fricção, segundo Padilla et al. (2005), é dado pelas variações de geometria na tocha; por exemplo, um loop no cabo da tocha aumenta em até 4 vezes a fricção, quando comparado a uma tocha linear e em condições de trabalho idênticas. Esta fricção maior devido a dobras no conduíte pode até fazer com que a velocidade de alimentação real seja menor do que a regulada, sem o usuário perceber. Para Huisman (2003), uma elevação da velocidade do arame provoca o crescimento do coeficiente de atrito entre arame e conduíte. Por outro lado, Padilla et al. (2003) mostraram haver independência entre a força para empurrar o arame através do alimentador e a velocidade de alimentação imposta, para velocidades mais altas, como em um intervalo de 10 a $18 \mathrm{~m} / \mathrm{min}$.

De acordo com Shimizu et al. (2006), existe fricção entre o arame e o bico de contato também devido ao aquecimento do bico de contato. Esta fricção torna-se maior ou menor em função do tipo de arame e da corrente de soldagem. A resistência à alimentação do arame pode flutuar de acordo com a condição do contato deslizante formado entre o bico de contato e o arame durante a soldagem. Quando esse contato deslizante se encontra em um estado estável de fusão, tanto o valor absoluto quanto a dispersão da resistência à alimentação do arame são baixos. Entretanto, quando o contato deslizante entra em um estado de repetição de derretimento e solidificação, tanto o valor absoluto quanto a dispersão aumentam.

Esta verificação de Shimizu et al. (2006) foi usada por eles para explicar a maior alimentabilidade de um arame não cobreado em relação a um cobreado. Eles determinaram, a partir de observações na superfície do arame, que o contato deslizante arame-bico de contato está num estado de constante derretimento para uso de arames não-cobreados, enquanto que para o uso de um arame cobreado, este estado de derretimento é intermitente, e isso acaba por afetar a alimentabilidade de arames maciços durante a soldagem. Esse fenômeno acaba por solidificar o arame na ponta do bico, o que causa um aumento gradual na força de alimentação, assim, a intermitência desse efeito (solidificação) é responsável por flutuações na velocidade e na força de alimentação, como concluíram esses autores.

Ainda segundo Lyttle (1982), a lubrificação da superfície do arame-eletrodo é um fator fundamental para a redução da componente de fricção da força de alimentação, proporcionando uma alimentabilidade superior. Uma aplicação eficiente da força de alimentação é fundamental para manter as boas características do arco. Entretanto, ainda segundo este especialista, o uso de limpador-lubrificante pode prejudicar a alimentação, caso contribua para acumulação de detritos e, consequentemente, para um aumento na resistência à alimentação.

De acordo com Padilla et al. (2003), flutuações de apenas $1 \%$ na velocidade de alimentação de arames de alumínio em soldagem MIG/MAG pode levar a comprimentos de arco irregulares, com flutuações de corrente e tensão, assim como deterioração da qualidade da soldagem em geral. Ou seja, flutuações na velocidade de alimentação devem ser evitadas. Para um melhor entendimento de tais flutuações da taxa de alimentação (aceleração ou queda súbita), a força de alimentação do arame deve ser levada em consideração, como cita Hajro e Hodžić (2004). Assim, este trabalho teve como objetivo investigar a influência de um "kit" comercial de limpeza e lubrificação sobre a operacionalidade do processo MIG/MAG com arame maciço, com ênfase na relação entre a força de alimentação/resistência bico de contato-arame, para arames com diferentes graus de contaminação e diferentes bicos de contatos. É importante destacar que problemas de alimentabilidade de arame não são exclusivos do processo MIG/MAG, podendo acontecer com arames tubulares e arco submerso, este último em menor escala por se usar arames de maior diâmetro e baixa velocidade de alimentação. Poderiam também estar presentes na alimentação de arame do processo TIG automatizado, mas também em menor escala, pois além da baixa velocidade de alimentação do arame, não existe passagem de corrente entre o bico (no caso de alimentação) e o arame. Por isto, este trabalho se restringiu ao processo MIG/MAG. 


\section{Metodologia}

A Figura 1 ilustra o "kit" para limpeza e lubrificação de arames no processo MIG/MAG utilizado neste trabalho e seu posicionamento no alimentador. Trata-se de um dispositivo disponível comercialmente, mas extremamente simples, composto de um grampo e um feltro quadrado. Esse feltro, que é dobrado na montagem para envolver toda superfície do arame, tem um caráter levemente abrasivo e já vem com a solução para limpeza e lubrificação (existem feltros para aços ao carbono e para alumínio e suas ligas). De acordo com o fabricante, os produtos de limpeza e lubrificação são livres de detergentes, ácidos, agentes abrasivos, carbono, sulfato, etc., não contém substâncias tóxicas, não é inflamável e não resseca ou evapora. Numa linha de produção, o "kit" deve ser substituído periodicamente (não são reutilizáveis). É importante ressaltar que o arame após passar pelo "kit" fica oleoso, perceptível ao tato.

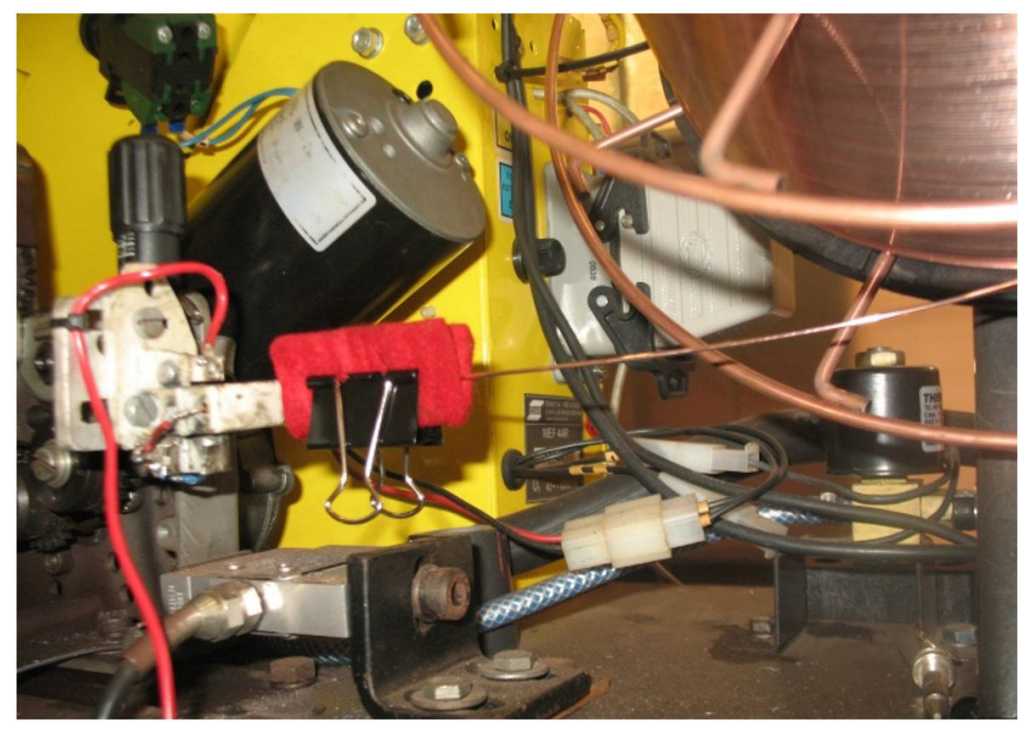

Figura 1. "Kit" (grampo e um feltro) de limpeza e lubrificação posicionado entre o rolo de arame e os roletes de alimentação, conforme instrução do fabricante em seu folheto de propaganda.

Foram planejadas comparações entre soldagens realizadas com e sem o conjunto de limpeza e lubrificação, com diferentes bicos de contato. A comparação se baseou principalmente quanto ao efeito do "kit" sobre o comportamento dos parâmetros força de alimentação, variação da resistência elétrica no contato entre o bico e o arame e aspecto visual do arame (endentações e variações de forma) ao sair da tocha. Também foi simulada a deterioração do arame quanto à contaminação por detritos industriais e oxidação ambiental. Como outro meio de verificação do comportamento do "kit", procurou-se observar o aspecto visual do arame após passar pela tocha (bico de contato e conduíte), após o uso ou não do "kit".

Antes de cada teste, características dimensionais dos arames utilizados foram avaliadas, de acordo com critérios da norma AWS SFA-5.18 (AWS, 2005), resumidamente explicados a seguir (tanto para permitir portabilidade de resultados, como por não ser assunto muito divulgado em artigos científicos):

a) Diâmetro Real: medido em milímetros, com o uso do micrômetro. Segundo a referida norma, para bitolas entre 0,80 e 1,60 mm, o diâmetro pode variar entre - 0,01 e + 0,04 mm;

b) "Cast": consiste em medir o diâmetro da circunferência, em milímetros, formada por um pequeno comprimento de arame quando este se encontra desenrolado sobre uma superfície, preferencialmente lisa. Para se realizar esta medida, retira-se cerca de 3 voltas de arame da bobina e coloca-se o arame retirado sobre uma superfície que não ofereça resistência ao seu desenrolamento natural, medindo-se o diâmetro da circunferência que este formará. A Figura 2 ilustra um exemplo de medição de "cast" e os valores deste parâmetro recomendados pela norma são apresentados na Tabela 1; 


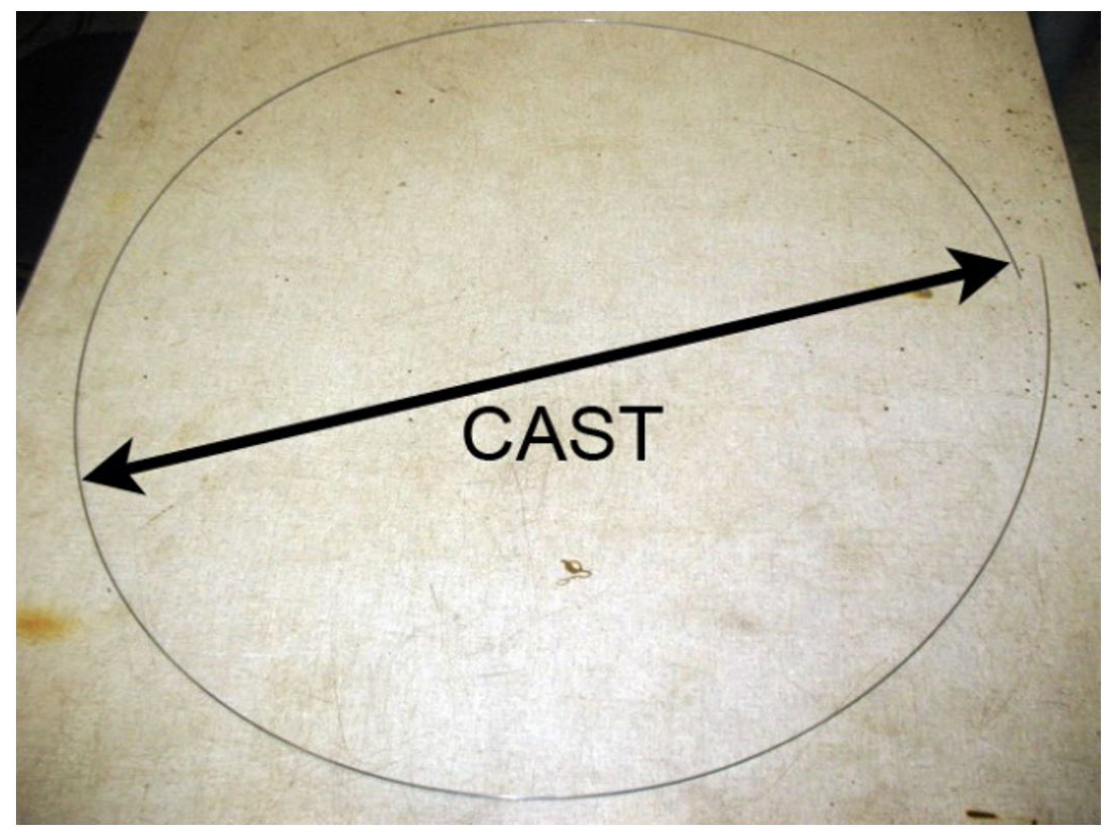

Figura 2. Ilustração da medição do "cast".

Tabela 1. Valores de "cast" em função do tipo de embalagem e da bitola do arame, segundo AWS SFA-5.18 (AWS, 2005).

\begin{tabular}{ccc}
\hline Tipo de Embalagem & Bitola do Arame [mm] & "Cast" [mm] \\
Bobinas de até 100 mm de diâmetro externo & qualquer & entre 100 e 230 \\
Outras & menor ou igual a $0,80 \mathrm{~mm}$ & maior ou igual a 300 \\
& maior ou igual a $0,90 \mathrm{~mm}$ & maior ou igual a 380 \\
\hline
\end{tabular}

c) "Helix": é a altura medida entre a ponta do arame e a superfície que este se encontra, também em milímetros. Sua medição é feita na mesma amostra retirada para obtenção do "cast", eliminando-se o excesso de arame que ultrapassa uma volta, e medindo-se a distância entre a ponta que não está em contato com a superfície e a ponta que está na superfície, como ilustrado pela Figura 3. A Tabela 2 apresenta os critérios de aceitabilidade desta característica;

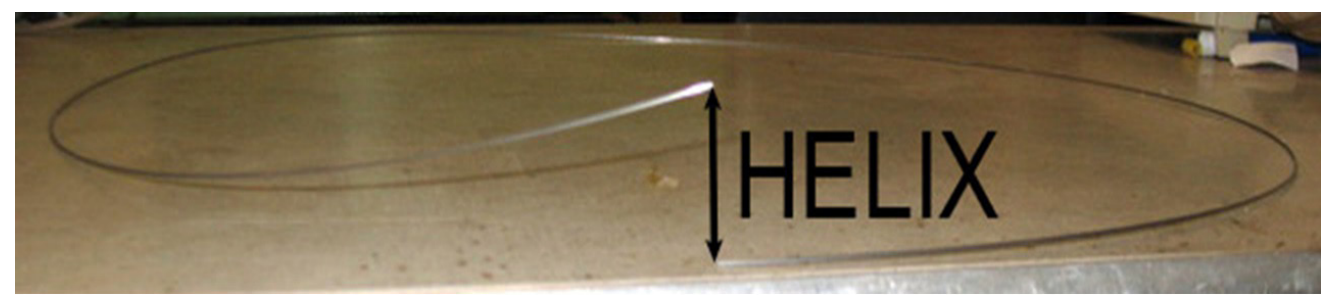

Figura 3. Ilustração da medição do "helix".

Tabela 2. Valores de "helix" em função do tipo de embalagem, segundo AWS SFA-5.18 (AWS, 2005).

\begin{tabular}{cl}
\hline Tipo de Embalagem & "Helix" [mm] \\
Bobinas de $100 \mathrm{~mm}$ de diâmetro externo & até $13 \mathrm{~mm}$ \\
Outras & até $25 \mathrm{~mm}$ \\
\hline
\end{tabular}


Além disto, visando a caracterização do arame, foi aplicado um teste extra não normalizado, mas comumente utilizado por fabricantes de arames que são fornecidos em barricas, a saber:

d)Torção Residual: é a rotação mínima medida (em graus), na ponta do arame curvada em $L$ a uma distância de 9 metros da bobina (Figura 4). É aceitável, para qualquer bitola de arame, uma rotação menor ou igual a 360 em um comprimento de aproximadamente $9144 \mathrm{~mm}$ (valor arbitrário transferido de unidade no sistema imperial) de arame esticado a partir da bobina.

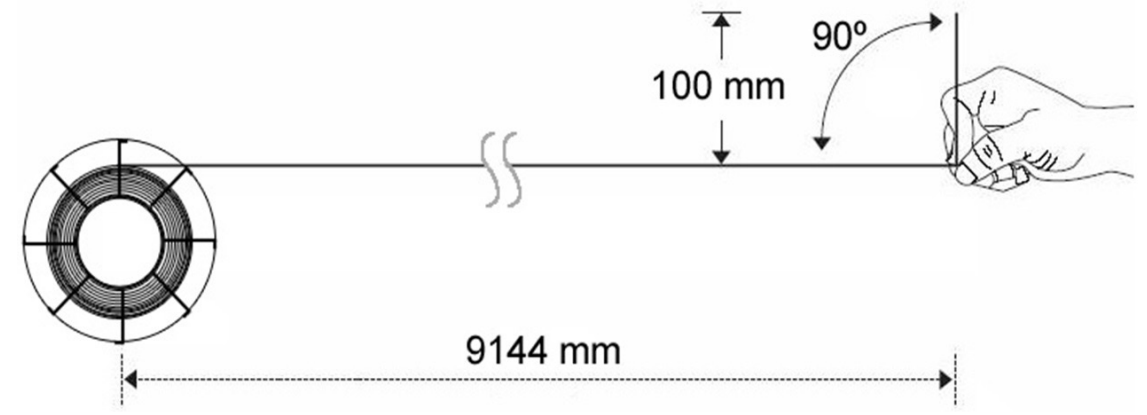

Figura 4. Ilustração da medição da torção residual.

O arame usado foi um da classe AWS ER70S-6 (segundo norma AWS SFA-5.18), de bitola 1,2 mm. Foram utilizados ao todo 2 bobinas dessa classe de arame, cuja caracterização nominal é mostrada na Tabela 3. Estas bobinas já tinham sido parcialmente usadas em cerca de 30 a $50 \%$ no volume de arame, portanto sendo uma amostragem do centro das bobinas. Para manter as mesmas condições para fins comparativos, trabalhou-se com a fonte no modo corrente constante (garantindo-se a mesma corrente em todos os testes). A velocidade de alimentação foi monitorada por meio de um "encoder" óptico.

Tabela 3. Caracterização das bobinas antes das séries de testes.

\begin{tabular}{ccccc}
\hline Bobina & ФNOMINAL & "Cast" & "Helix" & Torção Residual \\
1 & 1,19 & 730 & 0 & 180 \\
2 & 1,19 & 730 & 0 & 150 \\
\hline
\end{tabular}

Para se medir a resistência elétrica entre o arame e o bico de contato, usou-se o princípio da diferença de tensões medidas entre bico de contato-chapa $\left(\Delta \mathrm{V}_{\text {bico contato-chapa }}\right)$ e arame-chapa $\left(\Delta \mathrm{V}_{\text {arame-chapa }}\right)$, para esta última usando-se um dispositivo dedicado. Assim, a resistência no bico de contato foi calculada segundo a Equação 1:

$$
R_{\text {bico contato-arame }}=\left(\Delta V_{\text {arame-chapa }}-\Delta V_{\text {bico contato-chapa }}\right) / I_{\text {solda }}
$$

onde $\Delta V$ é a queda de tensão, em Volts, $I_{\text {solda }}$ a corrente de soldagem, em Ampère, e $R_{\text {bico contato-arame }}$ a resistência entre o bico de contato e o arame passando por dentro dele durante a soldagem, em Ohms.

Para se medir a força de alimentação, utilizou-se uma célula de carga adaptada na base do alimentador, técnica já descrita em diversos trabalhos (por exemplo, Kramer e Kahm, 1999; Hajro e Hodžić, 2004), incluindo a aplicação de um loop de 355 mm de diâmetro no cabo da tocha. Segundo Huisman (2003), uma bobina de arame de aço com massa de $16 \mathrm{~kg}$ tem uma inércia de cerca de $1 \mathrm{~kg} \cdot \mathrm{m}^{2}$, acumulando 0,6 Ws de energia cinética a uma velocidade de alimentação do arame de $20 \mathrm{~m} / \mathrm{min}$. Entretanto, esse autor acredita, baseado em seus resultados, que as forças de aceleração para a bobina sejam bem menores do que para a aceleração do próprio motor do alimentador. Mesmo assim, outra modificação imposta nesta técnica foi levar em conta o peso da bobina durante 
os testes e aplicar uma pré-carga. Para isto, antes de cada teste, a bobina de arame era pesada e, então, um ajuste do freio do alimentador era feito, com base na velocidade de alimentação $\left(V_{\mathrm{a}}\right)$, dada em $\mathrm{m} / \mathrm{min}$, e na massa da bobina $\left(m_{b}\right)$, em kg, de acordo com a Equação 2:

$$
\text { Carga_Inicial }=-0,39+0,08 \cdot V_{a}+0,13 \cdot m_{b}
$$

A carga inicial é o valor a ser lido durante a regulagem do mecanismo responsável pelo "travamento ou alívio" da bobina. Entretanto, para bobinas de pouca massa (até $3 \mathrm{~kg}$ ) ou velocidades de alimentação muito pequenas, o ajuste a ser feito adquire valores muito pequenos, menores do que a sensibilidade do mecanismo de travamento da bobina, tornando esse ajuste não-captável pelo sensor de carga. Mesmo assim, esse ajuste ainda atua no sentido de evitar o desembobinamento parcial, bem como variações na força de alimentação medida, criada por tensões dentro da própria bobina.

A primeira série de testes consistiu em soldar no modo goticular ("spray"), condição de alta velocidade de alimentação. Para tal, a corrente foi regulada em 270 A, obtendo-se uma velocidade de alimentação do arame de $8,3 \mathrm{~m} / \mathrm{min}$. Para manter um cordão típico de condições industriais, a velocidade de soldagem foi regulada em $40 \mathrm{~cm} / \mathrm{min}$. A distância do bico de contato-peça (DBCP) usada foi de $19 \mathrm{~mm}$. Foram feitas soldas nestas condições usando e não usando o "kit". Para verificar a influência do bico de contato, as soldas foram replicadas usando-se 3 diferentes bicos de contato comerciais, a saber, de cobre eletrolítico (E-Cu), de uma liga $\mathrm{Cu}-\mathrm{Cr}$-Zr e revestido de prata (HDS - Heavy Duty Silver). Para fins de verificação de repetibilidade, cada condição de teste foi feita 3 vezes.

Na segunda série de testes, usou-se as mesmas regulagens da primeira série (transferência goticular). Porém, o arame utilizado estava severamente oxidado ou contaminado com limalha de ferro. Também se utilizou bicos de E-Cu. Para simular um arame oxidado, mergulhou-se inteiramente a bobina em uma solução de água e sal por aproximadamente 15 minutos. Logo em seguida, retirou-se a bobina da solução e com o uso de um secador por ar quente eliminou-se o excesso da solução aderida à bobina. Esta então permaneceu em repouso em uma estufa a temperatura ambiente por quase uma semana. Já para contaminar o arame com detritos, o mesmo foi desenrolado de uma bobina e simultaneamente enrolado em outra, bem lentamente. Durante o processo, manteve-se $o$ arame passante imerso em limalha de ferro magnetizada. Para maior aderência, a limalha foi aderida também por contato direto com a superfície radial da bobina, com a ajuda de um ímã e, em seguida, foi feito o embobinamento do arame, de forma a prender a limalha entre as camadas de arame. Para o caso dos arames oxidados/contaminados, foi ainda aplicado um teste suplementar comparativo (com e sem uso do "kit") sem arco, observando-se o aspecto do arame ao sair da tocha.

Todos os testes de soldagem foram realizados na forma de simples deposição sobre chapa, com a tocha em posição perpendicular às chapas e usando-se $\mathrm{Ar}+12 \% \mathrm{CO}_{2}$ como gás de proteção. As chapas de teste foram fabricadas de aço ABNT 1020 (12,7 mm de espessura, $250 \mathrm{~mm}$ de comprimento e $75 \mathrm{~mm}$ de largura). A aplicação do feltro limpador-lubrificante foi feita conforme a Figura 1. Cada soldagem durou aproximadamente 2 minutos (tempo suficiente para simular condições severas de trabalho). Em cada teste, monitorou-se os parâmetros tensão, queda de tensão no bico de contato e força de alimentação. A velocidade de soldagem não foi monitorada em cada teste, mas o equipamento foi calibrado e tinha boa capacidade de manter a velocidade estável.

Uma mesma bobina foi usada nas séries de testes para comparar a influência dos 3 diferentes bicos de contato sobre a resistência elétrica e força de alimentação em soldagem no modo goticular ("spray"). Da outra bobina foi retirada uma amostra, através de rebobinação, para a série de teste na condição contaminada. O restante da bobina foi utilizado para a série de teste com o arame na condição oxidada. Por segurança, o ensaio de caracterização foi aplicado novamente em todas as bobinas. Como mostra a Tabela 4, as características se alteraram pouco, justificável, pois estas propriedades variam com a posição da amostra na bobina. Devido à amostra de arame na condição oxidada ter sido tirada mais no final da bobina, suas características se mostraram inferiores às demais, mas ainda aceitáveis conforme norma.

Tabela 4. Recaracterização das bobinas segundo norma AWS SFA-5.18 (AWS, 2005), após os testes.

\begin{tabular}{cccc}
\hline Identificação da bobina & “cast" [mm] & “Helix" [mm] & Torção residual (graus) \\
Usada nos testes com diferentes bicos & 630 & 8 & 90 \\
Usada no teste com arame oxidado & 640 & 25 & 180 \\
Usada no teste com arame contaminado & 630 & 6 & 90 \\
\hline
\end{tabular}




\section{Resultados e Discussões}

A Tabela 5 apresenta o sumário dos testes realizados. $\mathrm{O}$ aspecto geral dos cordões de solda foi satisfatório e bem uniforme em geometria e sanidade, tanto com a presença como com a ausência do limpador-lubrificante. Entretanto, na série de teste onde o arame se encontrava oxidado, foi impossível estabelecer um arco elétrico e, portanto, só a força de alimentação foi passível de aquisição para uma velocidade de alimentação regulada. A principal causa de impedimento da manutenção do arco para essa condição pôde ser averiguada por um simples teste de comparação da resistência elétrica bico de contato-arame, entre um arame normal e um arame oxidado, sem arco. Enquanto o ohmímetro mal registrava oscilação ou sequer valores baixos para a resistência do bico quando usado arame normal, para o arame oxidado a resistência oscilou entre $2 \Omega$ e $1000 \Omega$. Essa faixa de resistência foi capaz de isolar o contato arame-bico, não permitindo estabelecimento do arco.

Tabela 5. Resumo dos valores médios com desvios padrão resultantes das diferentes séries de testes.

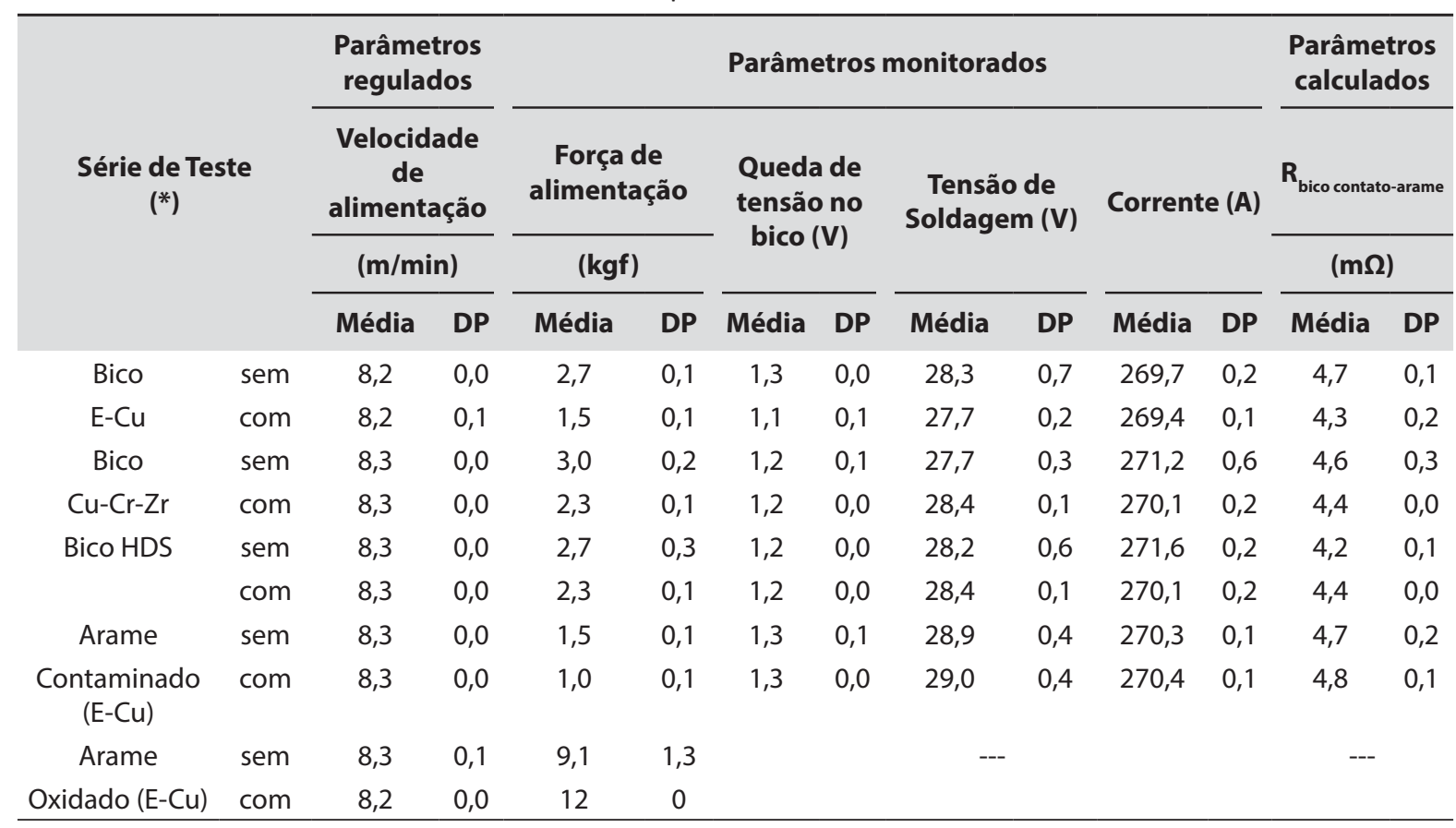

$\left({ }^{*}\right)$ - As palavras "sem" e "com" referem-se à condição de ausência e presença do "kit", respectivamente. Na condição de arame oxidado não se realizou medições com arco aberto.

\subsection{Resistência elétrica do bico de contato}

As resistências bico de contato-arame foram calculadas para todos os testes, exceto para a condição de arame oxidado. Os valores encontrados estão coerentes com os citados por Shimizu et al. (2006), para os quais a queda de tensão entre o bico de contato e o arame é em torno de $1 \mathrm{~V}$, e a resistência entre o bico de contato e o arame é da ordem de 4 a $7 \mathrm{~m} \Omega$. Os valores das resistências para as séries de testes com diferentes bicos de contato são estatisticamente (considerando os desvios padrão) iguais, como visto na Tabela 5, mostrando não haver influência do tipo de bico na resistência (como de certa forma esperado). Também fica evidente que o lubrificante, apesar de ficar aderido à superfície do arame, não afeta a resistência no bico de contato. Importante ressaltar que também não houve aumento ou diminuição da resistência elétrica ao longo do tempo de soldagem.

\subsection{Força de alimentação}

A força de alimentação foi o principal parâmetro de análise deste trabalho. Em geral, para a série 1 de testes, detectou-se uma redução na força de alimentação com o uso do limpador-lubrificante, redução variando de 0,4 a 1,5 kgf. Observou-se ainda menores desvios-padrão quando o limpador-lubrificante foi aplicado. 
Já os testes da série com arame contaminado apresentaram valores menores da força de alimentação, devido em grande parte ao ajuste de freios. Como comentado na seção 3, o ajuste funciona de forma deficiente para bobinas com menos de $3 \mathrm{~kg}$ ou com velocidades muito baixas, já que o mecanismo de travamento se trata de uma mola helicoidal pressionada por uma porca recartilhada, a qual comprime a bobina (Figura 5) de forma não linear. Assim, no caso da série de testes com arame contaminado, a pequena massa (em torno de $3 \mathrm{~kg}$ ) contribuiu para um ajuste não-sensível. Assim, apesar de terem valores diferentes, observa-se a mesma relação da força de alimentação entre o uso e o não uso de limpador-lubrificante dos demais testes.

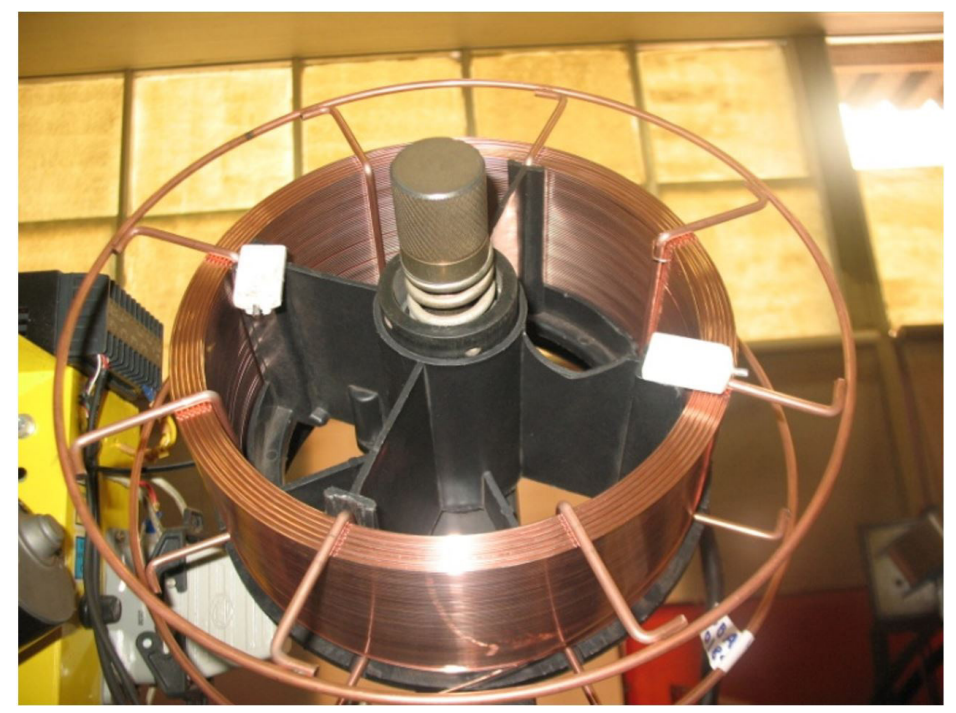

Figura 5. Destaque do mecanismo de travamento da bobina responsável pelo ajuste de freio, cuja principal função é evitar flutuações na força de alimentação medida.

Na série de testes com arame oxidado, foram feitos 3 testes de alimentação na condição sem e apenas 1 na condição com limpador-lubrificante, uma vez que não foi possível repetir esse teste, onde a célula de carga surpreendentemente alcançou, por vezes, a capacidade máxima (20 kgf). Durante a alimentação, notou-se muita trepidação na tocha e deslizamento dos roletes. Esses fatos corroboram as afirmações de Lyttle (1982) sobre os casos em que o lubrificante pode ser prejudicial ao sistema e à alimentabilidade. Nesse caso em especial, a força de alimentação aumentou significativamente com a adição de limpador-lubrificante, se comparada à não utilização do mesmo (Tabela 5). É importante ressaltar que mesmo sem limpador-lubrificante houve um aumento sensível na força de alimentação quando o arame se encontrava oxidado. Também houve um aumento da força de alimentação ao longo do tempo de soldagem.

\subsection{Considerações específicas do uso do "kit" em arame oxidado}

Outra constatação feita foi a destruição de parte do feltro limpador-lubrificante pelo arame oxidado. Normalmente, apenas uma mancha escura aparece no feltro após certo tempo de soldagem, mas com o uso do arame oxidado detectou-se a retirada de material do feltro (Figura 6a). Esperava-se que o feltro fosse capaz de limpar o arame, retirando parte da camada de óxido. Entretanto, o que se viu foi o arame oxidado retirando material do feltro. $\mathrm{O}$ aspecto do arame ao sair da tocha foi o mesmo, com ou sem a aplicação do limpador-lubrificante, como ilustrado pela Figura $6 \mathrm{~b}$.

\subsection{Considerações específicas do uso do "kit" em arame contaminado}

A limalha usada como meio de contaminação dos arames teve pouca aderência ao mesmo, apesar da metodologia usada. Na série de testes com arame contaminado, pelo simples movimento de rotação da bobina, parte do contaminante se desprendia durante o processo. O que restava no arame, devido ao magnetismo, acabou por aderir-se às guias metálicas e aos roletes do sistema de alimentação (Figura 7a). Assim, não houve presença perceptível ao olho nu do contaminante no arame ao sair da tocha (Figura 7b), apesar de se notar por tato estar 


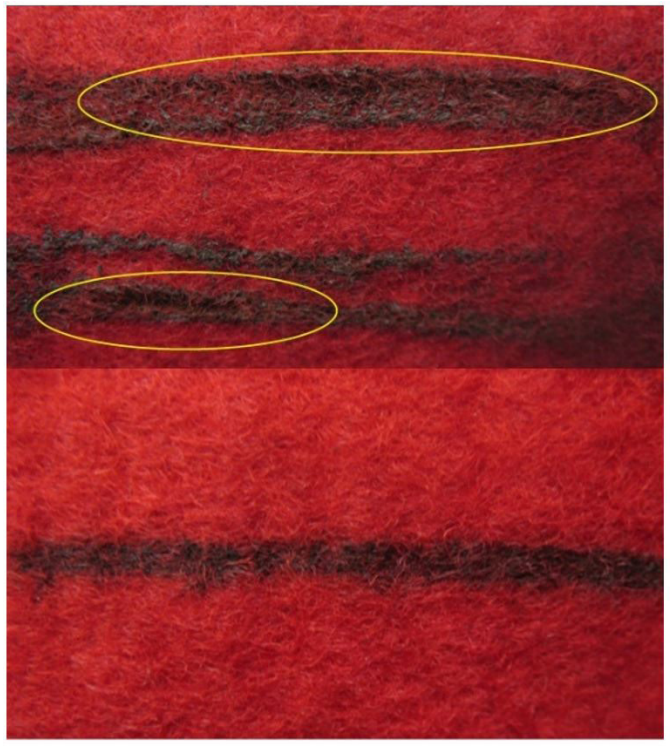

(a)

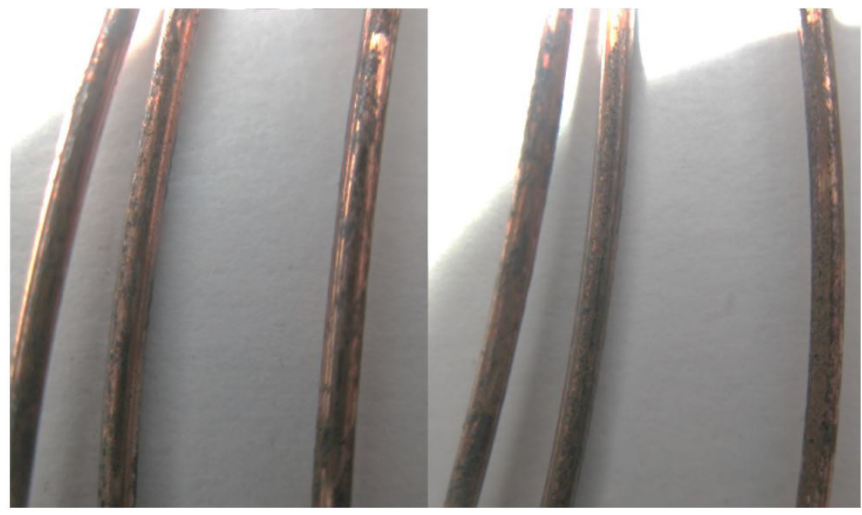

(b)

Figura 6. (a) marca impressa no feltro limpador-lubrificante durante o uso: com arame normal (abaixo), a marca é uniforme, enquanto que com arame oxidado (acima), é possível ver sulcos abertos pelo arame no feltro, além da irregularidade da marca; (b) aspecto do arame oxidado ao sair da tocha na condição sem arco: à esquerda, com o uso de limpador-lubrificante, e à direita, sem o uso do mesmo (visualmente não há redução da camada de óxido na presença do limpador-lubrificante).

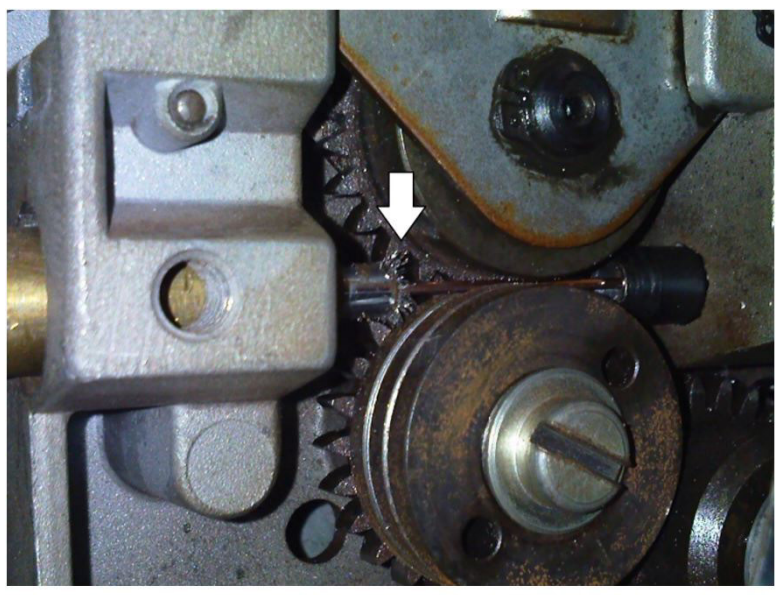

(a)

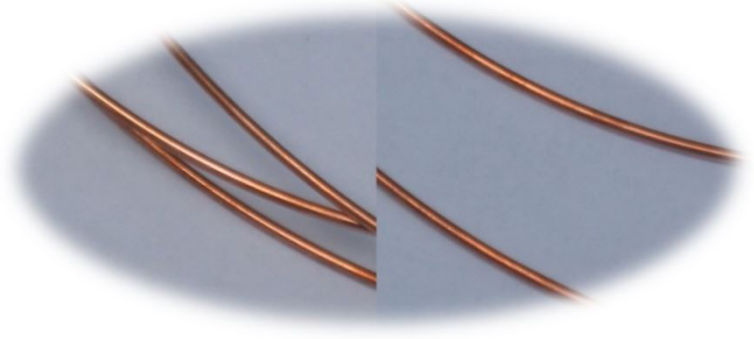

(b)

Figura 7. (a) retenção da limalha de ferro magnetizada nas pontas das guias e nos dentes do roletes (note o acúmulo nas pontas das guias, como indicado pela seta); (b) aspecto do arame contaminado, ao sair da tocha: à esquerda, com o uso do limpador-lubrificante, e à direita, sem o uso do mesmo (visualmente não se detecta a presença de contaminante em nenhum caso).

o arame com impureza na superfície: o aspecto do arame contaminado ao sair da tocha, com uso ou não de limpador-lubrificante, é o mesmo.

O que se viu com o uso do feltro limpador-lubrificante foi o impedimento da chegada dessas partículas ao sistema de alimentação, ou seja, nesse caso o feltro se mostrou efetivo como barreira mecânica, retirando a impureza do arame. 


\section{Conclusões}

Considerando as condições experimentais aplicadas e descritas neste trabalho, a primeira conclusão é acerca da influência do limpador-lubrificante sobre a resistência elétrica do bico de contato. Como os valores de comparação dessa resistência nos três testes da primeira série foram estatisticamente iguais, tanto entre si como entre presença e ausência de limpador-lubrificante ou entre diferentes bicos de contato, conclui-se que virtualmente não há alteração do referido parâmetro causada pelo limpador-lubrificante.

Com relação à força de alimentação, a mesma se reduz sensivelmente quando da aplicação do limpador-lubrificante, mas não ficou evidente que haja efeito do tipo de bico de soldagem usado sobre a força de alimentação.

O limpador-lubrificante mostrou-se capaz de remover detritos superficiais do arame sob alimentação, facilitando a alimentabilidade. Porém, apresentou efeito contrário quando do seu uso sobre arame oxidado. Assim, quanto à limpeza do arame, o "kit" é uma excelente barreira física contra contaminantes sólidos, mas não é capaz de remover camadas de óxidos, consequentemente não viabilizando soldagens com arames severamente oxidado.

\section{Agradecimentos}

Os autores deste trabalho gostariam de agradecer o apoio das empresas Binzel, Belgo-Bekaert e White Martins pelo fornecimento de material de consumo. Agradecem também ao Laprosolda pela disponibilidade laboratorial, indiretamente feita possível devido às agências de fomento CNPq, CAPES e Fapemig.

\section{Referências}

American Welding Society-AWS. AWS A5.18/A5.18M:2005. Specification for carbon steel electrodes and rods for gas shielded arc welding. Miami: AWS; 2005. 30 p.

Hajro I, Hodžić D. Development of devices for measurement of wire feeding force and feeding rate for GMAW. In: Proceedings of the 8th International Research/Expert Conference "Trends in the Development of Machinery and Associated Technology" (TMT 2004); 2004 September 15-19; Neum, Bosnia-Herzegovina. Bosnia-Herzegovina: University of Zenica; 2004. 4 p.

Huisman, G. Transport of the wire in MIG/MAG welding, especially friction. In: International Institute of Welding. Proceedings of the IIW Annual Assembly; 2003 July 7-9; Bucharest, Romania. Roissy: IIW; 2003. DOC XII-1776-03.

Kramer A, Kahm B. Method and system for determining the feedability of welding wire. United States patent US 5973291, 1999 Out 26.
Lyttle KA. Reliable GMAW means understanding wire quality, equipment and process variables. Welding Journal. 1982;61(1):43-48.

Padilla TM, Quinn TP, Munoz DR, Rorrer RAL, Berger JR. Dynamic factors contributing to buckling and birdnesting during GMAW wire feeding. In: American Welding Society. Proceedings of the AWS International Exposition and Annual Convention; 2005 April; Dallas, TX, USA. Miami: AWS; 2005. 5 p.

Padilla TM, Quinn TP, Munoz DR, Rorrer RAL. A mathematical model of wire feeding mechanisms in GMAW. Welding Journal. 2003;81(5):100s-109s.

Shimizu H, Itoh K, Masaie N, Kurokawa T, Ushio M. Feedability of wires during metal active gas welding. Science and Technology of Welding and Joining. 2006;11(1):81-93. http://dx.doi. org/10.1179/174329306X77876. 